\title{
EFFECT OF THE 7E INSTRUCTIONAL STRATEGY ON THE OVERALL ATTITUDE OF STUDENTS IN BIOLOGY IN PUBLIC SECONDARY SCHOOLS IN ADAMAWA STATE, NIGERIA
}

\author{
Abdullahi Shuaibu ${ }^{1,2}$ and Nor Asniza Ishak ${ }^{1 *}$ \\ ${ }^{1}$ School of Educational Studies, Universiti Sains Malaysia, \\ 11800 USM Pulau Pinang, Malaysia \\ ${ }^{2}$ Department of Environmental and Life Science Education, \\ Modibbo Adama University of Technology, P.M.B. 2076, \\ Yola, Adamawa State, Nigeria \\ *Corresponding author: asnizaishak@usm.my
}

Publication date: 23 December 2020

To cite this article: Abdullahi Shuaibu, \& Nor Asniza Ishak. (2020). Effect of the 7E instructional strategy on the overall attitude of students in biology in public secondary schools in Adamawa State, Nigeria. Asia Pacific Journal of Educators and Education, 35(2), 171-186. https://doi.org/10.21315/apjee2020.35.2.10

To link to this article: https://doi.org/10.21315/apjee2020.35.2.10

\begin{abstract}
The effect of attitude as a psychological construct that impacts students achievement in secondary schools have been widely reported, and the need to address that non-cognitive trait, so as to improve students' achievement have been stressed. Negative attitude of students have adversely affected educational outcomes and the need to improve this trait in students is the aim of this study. The study investigated the effect of the $7 \mathrm{E}$ instructional strategy on the overall attitude of students of the 11th grade, in Biology, in public secondary schools in Adamawa State, Nigeria. Four attitude constructs, namely; attitude towards Biology as a subject; attitude towards the Biology teacher; perception of importance of Biology and perception of difficulty of Biology; were used in the study. Two randomly selected schools were denoted as experimental and control groups and were taught using the 7E instructional strategy and the teacher-centered methods, respectively. A 38-item Likert-based questionnaire was used to collect data before and after intervention was given. The research question was answered by the means and standard deviations, while the hypothesis was analysed using the Analysis of Covariance (ANCOVA) statistics. The descriptive statistics results showed that the experimental group had higher mean scores in three out of the four attitude variables, while no significant difference was recorded on one variable. The overall attitude of students taught by the $7 \mathrm{E}$ instructional
\end{abstract}


strategy and when taught by traditional teacher-centered method, showed that students' attitude is positively affected, by the 7E instructional strategy. Therefore, 7E instructional strategy significantly improved students' attitude towards Biology.

Keywords: 7E instructional strategy, teacher-centered instructional methods, Biology, attitude, Nigeria

\section{INTRODUCTION}

Attitude, as viewed by Kind, Jones and Barmi (2007) is a concept that has different components, such as cognitive (knowledge, beliefs and ideas), behavioral (tendency towards an action) and affective (feelings, like and dislike). It is a concept that makes a person judgmental as to whether something or an object is harmful or beneficial, pleasant or unpleasant, good or bad, important or unimportant (Oluwatelure \& Oloruntegbe, 2010).

Attitude has also been described as the tendency to react in a way, negatively or positively, towards a given object or matter (Harrell, 2006). All students have an attitude towards learning, but the attitudes vary. Some individuals' attitude helps them to deal with obstacles and challenges, enabling them to achieve their learning objectives. Others have attitudes that slow them down, stopping them from achieving their learning objectives. Those having positive attitudes towards school accomplish significantly better academic achievement than those having negative attitude (Shah, 2009). This study investigates how a teaching intervention, using the 7E instructional strategy, would affect students' in different attitudinal constructs, beginning with their attitude towards Biology as a subject.

Students' attitude towards the Biology teacher has been found to be of crucial importance, in respect to their attitude towards the subject and their achievement in it. Dumaz (2007) and Telli, Barok, Tekkaya and Chakiroglu (2009), assert that positive attitude of students towards the teacher contributes significantly to students' learning outcome.

Similarly, perception of students to the importance of Biology is related to their overall attitude towards the subject, because it is then, easier to maintain their interest (Coker, 2009). The ability of students to see the relevance of Biology is based on making them see the connections between the subject and their everyday life experiences. 
Furthermore, students' perception of the difficulty of Biology is amplified by the inter-disciplinary nature of the subject. For instance, concepts of organic and inorganic molecules, chemical reactions, diffusion (Tekkaya, Ozkan, \& Sungur, 2006), as well as too many topics that need to be learned (Dumaz, 2007). These factors contribute to students' perception of Biology learning as difficult. Therefore, the study aims at determining the overall attitude of students regarding these attitude constructs as they relate to Biology.

\section{LITERATURE REVIEW}

Attitude towards schooling is a psychological construct depicting an individual's feelings, behaviour, judgement for school experiences and expression of an unfavourable or favourable affection (Candeias, Rabelo, \& Oliveira, 2013). Like other constructs, it is related to other psychological traits such as competence [often seen as a result of previous achievement] and students' perception of an interest in learning. Studies on students' attitude towards Biology have evolved as a targeted area of study because researchers have demonstrated the role attitude plays in students' academic achievement. These studies have been widely reported (Nasr \& Soltani, 2011), but the findings emanating from some of these studies are mixed in nature. For instance, some studies concluded that students are affected by the kind of pedagogy they experience in their science classes (Shruba, 2008; Koballa \& Glynn, 2007). Others believe that improvement in students' achievement and attitudes is not attained by instructional strategies that are innovative (Glynn, Taasoobshrazi, \& Brickmann, 2007). However, the need to address the effects of non-cognitive traits of individuals as they relate to educational outcomes had been highlighted by Borghans, Duckworth, Heckman and Weal (2008). The study emphasised that traits of personality (such as attitude) are less stable to maintain than abilities of cognition, therefore, educational authorities need to pay more attention to the effects these traits have on educational outcomes. To positively influence students' attitude, the learning cycle strategies, amongst which, is the 7E instructional strategy is advocated.

Studies on attitude using the learning cycle are less abundant in literature than achievement studies. Armbuster, Patel, Johnson and Weiss (2009) developed and implemented an instructional design focusing on employing active studentcentered pedagogy to teach Biology. The course was designed to consist: (i) rendering of the course content presentation to teach specific course content within a broad conceptual theme; (ii) active learning in every lecture and 
(iii) strategies that create more student-centered learning environment (Armbuster et al., 2009). Data was collected using a student survey. The restructuring of the course to follow student-centered design led to better attitudinal shift and selfreported student engagement.

Similarly, Connell, Donovan and Chambers (2016) investigated the effect of student-centered strategy on the attitude of students towards biology. The study determined the effect of teaching biology in an extensively student-centered manner with consistent formative assessment (active learning pedagogy), with moderate student-centered pedagogy which has fewer formative assessments and without grouping students. Data was collected using multiple questions and Multiple Regression was used to compare the post-assessment scores of the methods. The findings of the study revealed that students in the extensively student-centered pedagogical section exhibited a greater shift in their attitude towards biology.

Additionally, Cramer (2012) studied the impact of the learning cycle on the attitude of 7 th grade Biology students. The total of 68 students were used as sample in the pre-test, post-test quasi-experimental designed study. Data was collected through the Test of Science Related Attitude questionnaire and analysed by comparing average student responses to seven categories of questions presented in the questionnaire. The study findings showed a decrease in students' science related attitude towards Biology, which is probably related to stress associated with inquiry, which demands students' active participation in making meaning of scientific phenomena, instead of the familiar teacher-centered methods that provides all answers to passive students.

However, the study conducted by Shaheen and Kayani (2017) showed a different outcome. In the study, Shaheen and Kayani (2017) specifically employed the 7E instructional model and compared its effectiveness to the traditional method, as they affect students' attitude towards biology. The total of 122 students were used as sample, in a quasi-experimental pre-test, post-test control group design. The experimental group was treated with the $7 \mathrm{E}$ approach while the control group was taught traditionally. The equality of the groups in the pre-test in Biology Attitude Questionnaire (BAQ) and Integrated Science Process Skill Test (ISPST) was checked by using an Independent Sample $t$-test. ISPST was used as a covariate because there was a significant difference in the scores of students in the pre-test and post-test. Hence, ANCOVA and $t$-test were employed to test the post-test scores. The study found that the attitude of students in the experimental group was significantly better than that of the control group. The employment of this approach to study its effect on a student population that perennially demonstrates low achievement could be said to be desirable. When students' attitude is 
positive, effort put into learning biology concepts improve and this leads to better understanding and retention of knowledge.

\section{Attitude Towards the Biology Teacher}

The attitude of students towards the Biology teacher is of crucial importance regarding their attitude towards the subject and their achievement in it (Telli et al., 2009). Positive teacher-students interaction is an important variable in determining students' attitude towards the subject and is a significant contributing factor in students learning outcomes (Dumaz, 2007). Positive students' attitude towards the Biology teacher is effective for the realisation of learning outcomes and creating an environment conducive for learning (Cornelius-White, 2007). Students' attitude towards the Biology teacher could be achieved through active learning strategies, which is employed, to create excitement in the classroom and enhance learning (Eison, 2010). The 7E instructional model is an active learning strategy that promotes the exploration of concepts before the concept is even introduced, enabling students to compare their initial conceptions with the scientifically accepted notion of the concept (Mecit, 2006). The 7E model comprises of peer interaction through group discussions, which promotes social skills, learning support between individuals and a dynamic learning environment which allows for critical thinking (Telli et al., 2009). As the teacher facilitates students' interaction with the learning materials, a positive relationship develops, which engenders good feelings that leads to positive attitude in students towards the Biology teacher (Telli et al., 2009). This model would be employed in this study to compare students' attitude towards the Biology teacher in students taught using the 7E instructional strategy and those taught by the traditional, teachercentered methods of instruction, in public secondary schools in Nigeria.

\section{Perception of the Importance of Biology}

The attitude of students towards Biology is related to their perception of the importance of the subject, without which maintaining their interest is difficult (Coker, 2009). The ability of students to see the relevance of Biology is based on making them see the connections between the subject and everyday life experiences (Zeidan, 2010). The active and student-centered nature of the 7E instructional strategy, which has components such as "Elicit", "Explore" and "Extend" phases, enables the instructor to design activities that allow students to test their understanding of a concept by explaining and applying it to new context (Bordeaux \& Mosner, 2011). The 7E model also places the "Extend" after the "Elaborate" phase, to enable an instructor to ascertain the ability of students to transfer learning. This enables students to link Biological concepts, with the 
facilitation of the instructor, to everyday life and allows them to appreciate the importance of Biology to their lives (Coker, 2009). Himschoot (2012) reported that Biology topics relating to the human body help students to appreciate Biology as a subject. The topic of respiration was used in this study to enable students to better understand the organs, functions and operating mechanisms of respiration. The topic allows students to conceptualise on the diseases that could affect the respiratory system and personal habits that could endanger students' own respiratory health and so on. Employment of the 7E strategy would empower students to make connections between the topic, their personal selves and everyday experiences, which lead to appreciation of Biology and its importance. Biology topics, such as genetics, which deals with genotypes for predicting what future offspring would look like, DNA for solving crimes and so on, would certainly underscore the importance of Biology to students (Himschoot, 2012).

\section{Perception of the Difficulty of Biology}

Students perceive Biology as difficult because of the interdisciplinary nature of the subject (Tekkaya, Ozkan, \& Sungur, 2006). The study asserts that concepts of chemical reactions, diffusion, organic and inorganic molecules and so on, need to be mastered, to understand the chemical nature of biological concepts.

Biology is also perceived as difficult because there are many topics and concepts to be learned (Dumaz, 2007) and that secondary school Biology curricular is overloaded (Atilla, 2012). The topics are also difficult to learn due to the teaching styles adopted by Biology teachers and that Biology topics are difficult to learn because they are not applied to daily life situations (Kidman, 2008). This could cause students not to be happy with the way the subject is taught, thereby leading to negative attitudes towards Biology.

Ekici (2010) also corroborated the findings of Dumaz (2007), that the teaching technique employed by teachers to teach concepts and biological events that cannot be seen by the naked eyes makes Biology learning difficult. Because of these reasons, students are forced to memorise information.

Apart from the abstract nature of biological concepts, students study habits, as well as classroom learning environment, where students are overpopulated, also contribute to the difficulty of Biology perceived by students (Atilla, 2012). The aim of this study, among others, is to determine whether this perception of difficulty differs, between students in the experimental and control groups, after intervention with the 7E instructional strategy was given. 


\section{METHODOLOGY}

A quasi-experimental design (pre-test and post-test) was used for this study. Two public secondary schools having similar characteristics were randomly selected, while the experimental class was purposively selected due to the nature of $7 \mathrm{E}$ as a strategy of intervention. The strategy requires active conceptualisation through group discussions. A 38-item Likert-type, validated questionnaire was used as instrument for data collection. Instrument was administered to students prior to intervention (pre-test) and post intervention (post-test). Table 1 shows the research design.

Table 1. Research design

\begin{tabular}{cccccc}
\hline Group & Pre-test & Independent variable & Treatment & Post-test & 2nd post-test \\
\hline$(\mathrm{R})$ & $\mathrm{E}$ & $\mathrm{O}_{1}$ & $\mathrm{X}$ & $\mathrm{O}_{2}$ & $\mathrm{O}_{3}$ \\
$(\mathrm{R})$ & $\mathrm{C}$ & $\mathrm{O}_{1}$ & - & $\mathrm{O}_{2}$ & $\mathrm{O}_{3}$ \\
\hline
\end{tabular}

Notes: $\mathrm{R}=$ random assignment of schools to be selected for study; $\mathrm{E}=$ experimental group; $\mathrm{C}=$ control group; $\mathrm{O}_{\mathrm{I}}=$ measure of the dependent variable before treatment; $\mathrm{O}_{2}=$ measure of the dependent variable after treatment with independent variable; $\mathrm{X}=$ for the experimental group, indicates that it receives treatment; - = for the control group, indicates that it does not receive treatment; $\mathrm{O}_{3}=$ measure of the dependent variable after second Post-Test (Adapted from Campbell \& Stanley, 1966).

The schools out of which a sample was selected were in one of the five educational zones in the area of the study. The zone was selected through simple random sampling and selected zone is zone 1. The schools in zone 1 are 25 in number (Department for Planning, Research and Statistics (DPRS), 2015). The schools in this zone comprise of mixed (boys and girls) and single schools (boys only or girls only). However, the proportion of mixed schools is higher than single schools. These senior schools are populated by adolescent boys and girls within an age range of, mostly, 15-18 years. The choice of school for the study, for both the experimental and control groups, followed the simple random sampling strategy of sampling with replacement. The one class that was selected among several classes of Senior School II (SSII), constituted the sample. Purposive sampling was employed in determining the experimental class. This is because the study took place during normal school periods, in a school whose mode of instruction is teacher-centered.

A learning cycle classroom is activity-based, where conceptual understanding is achieved in a group-based, peer-driven approach. This may constitute a form of disturbance to students in other classes that demand absolute silence, as required in a teacher-centered learning approach. Therefore, purposive sampling was employed to allow the researcher to select a classroom that will constitute least 
interference to other classes. The control group class was selected by simple random sampling, since there is no variation with the normal methods of teaching. Consequently, one class of 60 students was selected for the experimental group. Another class of 60 students was similarly selected for the control group, making the sample of the study a total of 120 students. The duration of study is six weeks.

Ethical precaution was ensured through ensuring that the intervention was carried out during the school term and under normal classroom conditions. In other words, stipulated conditions where students' interest as stipulated by government were adhered to. No activity, whether field or laboratory, was conducted outside school hours. Risks, involving laboratory practical were closely guarded and maintained during the period of intervention.

Also, benefits of the study to participants, as well as community were explained to the school boards of the participating schools. Evaluation was carried out through a pretest-post-test 38 -item questionnaire, which addressed all the attitude constructs under investigation. Table 2 shows the number of items that addressed each of the constructs under investigation in the study.

Table 2. Number of questions for attitude sub-constructs

\begin{tabular}{lcc}
\hline Attitude sub-construct & $\begin{array}{c}\text { Number of } \\
\text { questions }\end{array}$ & Sample questions \\
\hline Attitude towards Biology & 13 & $\begin{array}{c}\text { Biology is fascinating and fun. } \\
\text { My Biology teacher helps to develop } \\
\text { my thinking. }\end{array}$ \\
$\begin{array}{lcc}\text { Perception of importance of Biology } & 7 & \text { Progress in Biology improves } \\
\text { the quality of our lives. }\end{array}$ \\
\begin{tabular}{l} 
Perception on difficulty of Biology \\
\hline
\end{tabular} & 8 & Biology lessons are difficult for me. \\
\hline
\end{tabular}

\section{RESULTS}

A descriptive statistic for the four constructs of attitude, which were used to derive data is given to show a general description of students' response, on the various attitudinal constructs. The research question, which seeks to determine the overall attitudinal response was also answered by the descriptive statistics which provides the means and standard deviations, while the Analysis of Covariance (ANCOVA) was used to analyse the hypothesis. Table 3 shows the descriptive statistics of the four attitude constructs. 
Table 3. Descriptive statistics of the four attitude constructs

\begin{tabular}{lcccc}
\hline \multicolumn{5}{c}{ Descriptive Statistics } \\
\hline & Group & Mean & SD & N \\
\hline POST ATT attitude of students towards & control & 31.90 & 4.06 & 60 \\
Biology & experiment & 35.15 & 2.25 & 60 \\
POST ATT attitude of students towards & control & 31.13 & 3.41 & 60 \\
Biology teacher & experiment & 38.42 & 1.84 & 60 \\
POST ATT perception of importance of & control & 21.33 & 2.938 & 60 \\
Biology & experiment & 28.37 & 1.45 & 60 \\
POST ATT attitude perception on difficulty & control & 24.75 & 1.81 & 60 \\
of Biology & experiment & 23.77 & 1.24 & 60 \\
\hline
\end{tabular}

The experimental group had a higher mean score in three out of the four constructs under investigation. For instance, for the of students' attitude towards Biology as a subject, the mean score of experimental group is 35.15, while that of the control group is 31.90. Similarly, the mean score of the experimental group for the construct of students' attitude towards the Biology teacher is 38.42 , which is higher than that of the control group that is 31.13 . For students' perception of the importance of Biology, the mean score of the experimental group is 28.37, which is higher than that of the control group that is 21.33 . However, no difference was observed between the experimental and control groups, when it comes to students' perception of difficulty of Biology. The mean score of the experimental group is 23.77 while that of the control group is 24.75 . This paper sought to determine the overall attitude of students, when all the various attitudinal constructs are combined.

\section{Research Question: What is the overall attitude of students towards Biology when they were taught by the $7 \mathrm{E}$ instructional strategy?}

Table 4 shows the descriptive statistics for overall attitude.

Table 4. Descriptive statistics for overall attitude

\begin{tabular}{lccc}
\hline \multicolumn{4}{l}{ Descriptive Statistics } \\
\hline \multicolumn{4}{l}{ Dependent variable: POSTATTITUDE } \\
\hline Group & Mean & SD & $N$ \\
\hline Control & 109.11 & 8.95 & 60 \\
Experiment & 125.70 & 4.16 & 60 \\
\hline
\end{tabular}


Overall, the attitude of students, regarding to all the variables under consideration, favours the experimental group (Mean $=125.70)$ than the control group (Mean $=109.11)$. Therefore, the overall attitude of students towards Biology, is positively affected in the experimental group than in the control group.

Hypothesis: There is no significant difference in the overall attitude of students when taught by the 7E instructional strategy and when taught by the traditional methods.

The one-way ANCOVA statistics that explains the overall attitude of students towards Biology between the experimental and control groups is presented in Table 5.

Table 5. Test of between-subject effects for overall attitude

\begin{tabular}{lcrrrrc}
\hline \multicolumn{1}{l}{ Tests of Between-Subjects Effects } \\
\hline Dependent variable: POSTATTITUDE & $\begin{array}{c}\text { Type III sum } \\
\text { of squares }\end{array}$ & df & $\begin{array}{c}\text { Mean } \\
\text { Square }\end{array}$ & $F$ & Sig. & $\begin{array}{c}\text { Partial eta } \\
\text { squared }\end{array}$ \\
\hline Source & $8290.98^{\mathrm{a}}$ & 2 & 4145.49 & 84.82 & 0.000 & 0.59 \\
\hline Corrected Model & 5352.49 & 1 & 5352.49 & 109.52 & 0.000 & 0.48 \\
Intercept & 40.77 & 1 & 40.77 & 0.83 & 0.363 & 0.08 \\
PREATTITUDE & 8274.26 & 1 & 8274.26 & 169.30 & 0.000 & 0.60 \\
Group & 5718.00 & 117 & 48.87 & & & \\
Error & & & & & & \\
\hline
\end{tabular}

The result shows the analysis of between-groups, comparing the effectiveness of the 7E treatment on the experimental group over the traditional instruction methods employed on the control group on the overall attitude of students in Biology. A significant difference between the experimental and control groups was found, $\mathrm{F}(1,117)=169 ; p=0.000$, which is less than 0.05 and an effect size $=0.60$ is obtained. This effect size translates that $60 \%(0.60 \times 100)$ of the difference between the experimental and control groups is due to the employment of the 7E strategy. The null hypothesis is therefore rejected.

\section{DISCUSSION}

The non-cognitive aspect of student behaviour, such as attitude, has been shown to affect students' academic achievement. The need to pay attention to the effect of personality traits have been emphasised because they are less stable to maintain (Borghans et al., 2008). Maintaining interest and positive attitude is one 
of the reasons that educationist are continually advocating for new instructional strategies with a view to achieving the desired instructional outcomes (Ahmed \& Abimbola, 2011).

The 7E instructional strategy was employed in this study to determine its effect on students' attitude towards Biology as a subject. The result showed significant improvement in students' attitude, when they were taught respiration, than when the students were taught using teacher-centered methods. This finding is in agreement with the findings of Shaheen and Kayani (2017).

Similarly, students' attitude towards the Biology teacher is crucial for achieving instructional objectives and this can be achieved through positive student-teacher interactions (Dumaz, 2007). Student-centred instructional methods allow for this type of interaction because the teacher is a facilitator of learning through active learning strategies (Eison, 2010). This enables students to create links between concepts and relate how these concepts apply to their daily lives affects their feelings and dispositions towards the subjects they study. In other words, providing students with the applicability of concepts in practical ways that they can relate to, enables a change in attitude towards Biology. For example, the application of anaerobic respiration in the making of food products, such as yoghurt and buns, as well as food drinks, through active learning, endears students to the subject. Also, examples that are personal in nature can aid conceptualisation of the respiration concept. For example, lactic acid formation that leads to oxygen debt during exercises and the mechanism of repaying such debts provide relatable examples that aid conceptualisation. This underscores the importance of Biology to the students and fosters a positive attitude towards the subject. Enabling proper conceptualisation also endears the Biology teacher to students. Students appreciate the Biology teacher when conceptualising a biological phenomenon becomes difficult by simply relating it to their previous conception about it. It leads to a positive attitude towards the subject.

The 7E instructional strategy allows Biology students to explore concepts till they reach equilibrium, where their own conceptions do not make sense to them. The teacher then facilitates how to reach equilibrium, which makes students happy and the teacher is endeared to them.

The 7E strategy also comprises of peer interaction, which gives students the freedom to interact and discuss, leading to the promotion of social skills and a dynamic environment for learning that is driven by critical thinking (Telli et al., 2009). 
In addition, the perception of students on the importance of a subject is highly related to their attitude towards the subject (Coker, 2009). If students are able to see the relevance of Biology through connecting Biology phenomena to their everyday life experiences, their attitude improves for the better (Zeidan, 2010). In this study, 7E instructional strategy was employed to show how respiration affects the personal lives of the students, as it affects their organs, livelihood and the application of the concept in their everyday lives. Biology topics relating to the human body enables students to appreciate the subject and see the workings of the subject in their personal lives (Himschoot, 2012).

Various reasons are responsible for students' perception that the subject of Biology is difficult. From the abstract nature of the subject (Atilla, 2012), to the interdisciplinary nature of biology (Tekkaya et al., 2006), as well as the many topics students are required to study at the secondary school level (Dumaz, 2007). Employing the student-centered $7 E$ instructional strategy did not change this perception of difficulty, when compared to the traditional teacher-centered instructional method.

To answer the question of the effect of 7E instructional strategy on the overall attitude of students towards Biology, the grand mean and standard deviations for all the sub-constructs under the attitude variable were computed and an ANCOVA statistical tool was used to find the students' attitude overall. The cumulative means showed that the experimental group has a higher mean score $($ Mean $=125.70)$ than the control group (Mean = 109.11). This means that overall, the 7E instructional strategy positively affects students' attitude towards Biology.

In addition, the ANCOVA statistical analysis confirmed this assertion. The results of the analysis showed that $p<0.05$, with an effect size of 0.60 . This effect size translates that $60 \%(0.60 \times 100)$ of the difference between the experimental and control groups is due to the employment of the 7E strategy.

This finding agrees with the findings of Bulbul (2010), who reported that the 7E instructional strategy has an overall effect on students' attitude due to its very nature of being a constructivist approach towards learning. According to the study, the 7E strategy encourages all sorts of communications between students, such that they can think critically about biological phenomena.

Similarly, Orunaboka (2011) states that active learning strategies encourage the development of positive attitudes in all science students in Nigeria. This is because of the inclusive nature of constructivist methods where students can individually 
construct their own knowledge by relating new phenomena with pre-existing conception (Prokop, Prokop, \& Tunnicliffe, 2007). When such conceptions are wrong, the instructor facilitates correcting such misconceptions through relatable examples that makes sense to the students (Gok, 2014). This foster and sustains a positive attitude that positively regulates behaviour. The $7 \mathrm{E}$ instructional strategy allows this to happen (Gok, 2014).

In addition, Anwar, Iqbal and Hussein (2012), assert that instructional strategies that create links between concepts induce positive attitudes in secondary school students. For instance, Biology curriculum in secondary schools is packed with topics that are primarily fundamental in nature. To foster positive attitude for Biology, these topics should make meaning to students, such that they can be able to relate to them and between them. The 7E instructional strategy demands that linkages between topics should be made. Attitude reflects how a person conceives a thing, therefore making Biology attractive and meaningful to students using the $7 \mathrm{E}$ instructional strategy will regulate the behaviour of students and can lead to the acquisition of positive overall students' attitude towards Biology.

This finding could be related to the Expectancy-Value Theory (EVT), which is a theory that ties "Effort" to the achievement of a "Valence" (Reward) through the "Instrumentality" of a strategy (7E instructional strategy). For example, the 7E strategy has phases that allow students to "Explore" concepts to find meaning, "Explain" these concepts to themselves as a group, and to the class in general, to determine correct conceptualisation and the "Extend" phase, to apply Biological phenomena to daily live situations. These phases enable students to put in the necessary "Effort" through the "Instrumentality" of the activity component of the 7E strategy to achieve the "Valence" or "Reward", which in this study, is attitudinal change of students towards Biology. The use of EVT for changing personality traits, such attitude and interest, using a strategy (in this study, the 7E instructional strategy) agrees with the assertion of Magidson, Roberts, CollardoRodriguez and Lejuez (2014), who maintained that the theory is appropriate for use in studies relating to personality traits.

\section{CONCLUSION}

The finding of this study has demonstrated that students' attitude is significantly affected by the strategy of instruction that is employed by their teachers. It also demonstrates that students' attitude towards their teachers as well as their perception of the importance Biology in there is significantly improved. However, 
the perception students that Biology is difficult has not been significantly affected by using $7 \mathrm{E}$ instructional strategy as a teaching resource. The $7 \mathrm{E}$ instructional strategy, therefore, is recommended for use in teaching Biology, especially for those concepts that students find difficulties in conceptualising.

\section{REFERENCES}

Ahmed, M. A., \& Abimbola, I. O. (2011). Influence of teaching experience and school location on biology teachers' rating of difficulty levels of nutrition concepts in Ilorin, Nigeria. Journal of Science, Technology, Mathematics and Education, $7(2), 52-61$.

Anwar, M., Iqbal, H. M., \& Hussein, C. (2012). Attitude towards Science: A case of Pakistan. Pakistan Journal of Social and Clinical Psychology, 10(1), 3-9.

Armbuster, P., Patel, M., Johnson, E., \& Weiss, M. (2009). Active learning and studentcentered pedagogy improve students' attitude and performance in introductory Biology. CBE Life Sciences Education, 8, 203-213. https://doi.org/10.1187/ cbe.09-03-0025

Atilla, C. (2012). What makes Biology learning difficult and effective: Students' views. Educational Research and Review, 7(3), 61-71.

Bordeaux, L., \& Mosner, C. (2011). Learning knowledge and understanding in Todd County public schools. Retrieved from http://www.tcsdk12.org/framework files/2013/08/4constructivism.pdf

Borghans, L., Duckworth, A. L., Heckman, J. J., \& Weal, B. T. (2008). The economics and psychology of personality traits. IZA Discussion Paper, 3333. https://doi. org/10.3386/w13810

Bulbul, Y. (2010). Effects of $7 E$ learning cycle model accompanied with computer animations on understanding diffusion and osmosis concepts. Unpublished Doctoral dissertation, Middle East Technical University, Ankara, Turkey.

Campbell, D. T., \& Stanley, J. C. (1966). Experimental and quasi-experimental designs for research and teaching. In N. L. Gagne (Ed.) Handbook of research on teaching (Chapter 5). Chicago: Round McNally.

Candeias, A. A., Rabelo N., \& Oliveira, M. (2013). Students' attitude towards learning and school-study of exploratory models about the effects of socio-demographics and personal attributes. Retrieved 25 February 2015 from. http//www.projectored. uebora.pt/document6/LICE.pdf

Coker, J. (2009). Reinventing life: Introductory Biology for a rapidly evolving world. American Biology Teacher, 71(5), 281-284. https://doi.org/10.2307/27669431 
Connell, G. L., Donovan, D. A., \& Chambers, T. O. (2016). Increasing the use of studentcentered pedagogies from moderate to high improves student learning and attitude about Biology. CBE Life Sciences Education, 15, 1-5. https://doi.org/10.1187/ cbe. 15-03-0062

Cornelius-White, J. (2007). Learner-centered teacher-student relationships are effective: A meta-analysis. Review of Educational Research, 77(1), 113-143. https://doi .org/10.3102/003465430298563

Cramer, K. R. (2012). Impact of constructivism via the biological science curriculum study (BSCS) $5 E$ model on students' achievement and attitude. Unpublished Master thesis, Montana State University.

Department of Planning, Research and Statistics (2015). Records unit. Adamawa State Ministry of Education, Nigeria.

Dumaz, B. (2007). The effect concept cartoons to the success of students and sensory features in the constructivist science teaching. Unpublished Master thesis, Mugla University, Mugla, Turkey.

Eison, J. (2010). Using active learning instructional strategies to create excitement and enhance learning. Retrieved from https://citeseerx.ist.psu.edu/viewdoc/ download?doi=10.1.1.456.7986\&rep=rep1\&type $=$ pdf

Ekici, G. (2010). An examination of the high school students' perception about biology laboratory environment education. E-Journal of New World Science Academy, $5(3), 180-186$.

Glynn, S. M., Taasoobshrazi, G., \& Brickman, P. (2007). Non-science majors learning science: A theoretical model of motivation. Journal of Research in Science Teaching, 44(8), 1088-1107. https://doi.org/10.1002/tea.20181

Gok, G. (2014). The effect of the 7e learning cycle on the $6^{\text {th }}$ grade students' conceptual understanding of human body systems, self-regulation, scientific epistemological believe and science process skills. Unpublished Doctoral dissertation, Middle East Technical University, Ankara, Turkey.

Harrell, K. (2006). Attitude is everything. New York: Collins Publishers.

Himschoot, A. R. (2012). Students' perception of relevance of biology content to everyday life: A study of higher education biology courses. Faculty Scholarship-Biology (Paper 2). Retrieved from https://digitalcommons.olivet .edu/cgi/viewcontent.cgi?referer=https://www.google.com/\&httpsredir=1 \&article $=1001 \&$ context $=$ biol_facp

Kidman, G. (2008). Asking students: What key ideas would make classroom biology interesting? Teaching Science, 54(2), 34-38.

Kind, P. M., Jones, K., \& Barmi, P. (2007). Developing attitude towards science education. Journal of Attitude towards Science Education, 29(7), 871-893. https://doi.org/ 10.1080/09500690600909091

Koballa, T. R., \& Glynn, S. M. (2007). Attitudinal and motivational constructs in science learning. In S. K. Abell \& N. G. Lederman (Eds.), Handbook of research on science education (Chapter 4). Mahwah, NJ: Lawrence Earlbaum Associates. 
Magidson, J. F., Roberts, B. W., Collardo-Rodriguez, A., \& Lejuez, C. W. (2014). Theory-driven intervention for changing pesonality: Expectation-value theory, behavioral activation and conscientiousness. Developmental Psychology, 50(5), 1442-1450. https://doi.org/10.1037/a0030583

Mecit, O. (2006). The effect of the $7 E$ learning cycle model on the improvement of $5^{\text {th }}$ grade students' critical thinking skills. Unpublished Doctoral dissertation, Middle East Technical University, Ankara, Turkey.

Nasr, A. R., \& Soltani, A. K. (2011). Attitude towards biology and its effects on student's achievement. International Journal of Biology, 3(4), 100.

Oluwatelure, T., \& Oloruntegbe, K. O. (2010). Review: Effects of parental involvement on students' attitude and performance in science. Journal of Microbiology Research, 4(1), 1-9.

Orunaboka, T. T. (2011). Attitude of Nigerian secondary school students towards physical education as a predictor of achievement in the subject. Journal of Education and Practice, 2(6), 71-79.

Prokop, P., Prokop, M., \& Tunnicliffe, S. D. (2007). Is biology boring? Students' attitude towards biology. Journal of Biology Education, 42(1), 36-39. https://doi.org/ $10.1080 / 00219266.2007 .9656105$

Shah, N. (2009). Theory of earning, “operant conditioning” by Skinner, B.F. Retrieved 25 February 2016, from http://research-education,edu.blogspot.com/2009/04/ theory-of-learning-operant-conditioning html

Shaheen, M. N. K., \& Kayani, M. M. (2017). Improving students' attitude towards biology as a school subject: Do instructional models really work? Journal of Applied Environmental and Biological Sciences, 7(1), 170-179.

Shruba, A. E. (2008). Evaluation of students' attitude towards science and self-efficacy in a non-majors college biology course. Unpublished Master thesis, Christian College, Fortworth, Texas.

Tekkaya, C., Ozkan O., \& Sungur, S. (2006). Biology concepts considered as difficult by Turkish high school students. Journal of Hacettepe University Faculty of Education, 21, 145-150.

Telli, S., Barok, P., Tekkaya, C., \& Chakiroglu, J. (2009). Turkish students' perception of biology learning environment: The effect of gender and grade level. Asian Journal of Research and Synthesis, 1(1), 110-124.

Zeidan, A. (2010). The relationship between Grade 11 Palestinian students towards biology and their perception of the biology learning environment. International Journal of Science and Mathematics Education, 8, 783-800. https://doi.org/10.1007/ s10763-009-9185-8 